\title{
Non-isolated LLC resonant DC-DC converter with balanced rectifying current and stress
}

\author{
AbdulHakeem Mohammed Dobi ${ }^{1}$, Mohd Rodhi Sahid ${ }^{2}$ \\ ${ }^{1}$ Department of Electrical Power, School of Electrical Engineering, Faculty of Engineering, \\ Universiti Teknologi Malaysia (UTM), Malaysia \\ ${ }^{1,2}$ Department of Electrical Engineering, College of Engineering, Waziri Umaru Federal Polytechnic, Nigeria
}

\begin{tabular}{l} 
Article Info \\
\hline Article history: \\
Received Aug 10, 2019 \\
Revised Nov 11, 2019 \\
Accepted Nov 25, 2019 \\
\hline
\end{tabular}

\section{Keywords:}

Current unbalance

DC-DC converter

LLC resonant converter

ZCS

ZVS

\begin{abstract}
In isolated type LLC resonant converters, transformer leakage inductances can be merged with the resonant inductor to extend the ZVS capability of the switches apart from isolation and voltage scaling. However, the transformer presents a resonant imbalance in the secondary side leading to secondary current unbalance, an increase in RMS value of the secondary current and increase thermal stress. This paper proposed a half-bridge non-isolated LLC resonant converter with a balanced rectifying current and stress in the rectifier diodes. The proposed converter can achieve the most advantages of isolated LLC converters, such as ZVS and low MOSFET turn-off loss. By the non-isolation method, secondary current and, transformer loss is significantly reduced. In addition, rectifier diodes operate with zero current switching and balanced rectifying current and stress over the entire operating range. The proposed non-isolated structure is verified by the experimental result with a $60 \mathrm{~W}$ LLC resonant converter.
\end{abstract}

Copyright (0 2020 Institute of Advanced Engineering and Science. All rights reserved.

\section{Corresponding Author:}

AbdulHakeem Mohammed Dobi, Department of Electrical Power System, Universiti Teknologi Malaysia (UTM), Malaysia. Email: amdobi2@live.utm.my

\section{INTRODUCTION}

Size optimization and power conversion efficiency of the power converter are emerging as a goal in the industrial application, due to benefits which include low power consumption, reduced thermal/electrical stress and cost. Resonant converters, unlike PWM converters, can be operated at high frequency to attain high power density [1] with a reduced size of passive components and filters [2] which are the major contributor of weight, volume, and cost of power converters.

Among the resonant converters, an LLC resonant converter is one of the most prevalent resonant topologies widely adopted in various applications [2] such as portable electronics, flat panel display, handheld devices such as notebook PC, smartphone, MP3 player. This is owing to their advantageous features such as output voltage regulation over wide load and line variation under narrow variation of operating frequency, low EMI emission, high efficiency. and soft-switching capability [3, 4]. Soft switching commutation of the power switches increases the efficiency of this converter, in addition to eliminating the reverse recovery effect of the rectifier diodes [5-8]. To ensure the zero voltage switching (ZVS) capability of the primary switches, there should be enough current in the primary circuit to charge and discharge the parasitic capacitance of the power MOSFETs, this is achieved by using a series inductor or by increasing the leakage inductance of the transformer [9]. However, this is at the expense of bulky magnetic components.

For the reason of miniaturizing LLC resonant converters, research attention is now focusing on magnetic integration as a solution to the size reduction of passive components. The general idea behind the concept of "Integrated magnetics" is to have a magnetic design in which various inductive elements are 
combined into a single magnetic core as reported in the literature [10-14]. Integration of magnetizing inductances and the resonant inductor $(L r \& L m)$ into the structure of the transformer has been reported in [15] to improve power density and reduce the core loss.

Thus, some major drawback of magnetic integration is the difficulty in controlling the magnitude of the leakage inductances during manufacturing process [10] which lead to resonant imbalance, high conduction loss owing to fringing effect [7]. The resonant imbalance causes a rectifying current imbalance per half switching cycle and thermal stress in the rectifier diodes, component mismatch and different phase gain in a multilevel inverter [14]. In [13] the effect of parameter mismatch in interleaved LLC resonant converter is compensated by controlling the commutation time of the synchronous switch, and the current unbalance is reduced to the lower peak. Though this approach proves to be very successful, it is faced with a complex control scheme. Liu et al. [16] proposed a Zero-Voltage Switching PWM (ZVS PWM). The proposed ZVS PWM consists of two operation modes and by alternating the two operations modes the input capacitor current balancing is achieved in a half-bridge three-level dc-dc converter (HBTL). Perhaps this approach is limited to continuous conduction modes of operation.

Non-isolated PWM converters reported in [17-19] highlight their benefits with respect to low driven and conduction loss. These benefits of non-isolated structure in PWM converters can be extended to resonant converters. In an application such as low photovoltaic (PV) charging system, spacecraft power supplies, and electric drives, where galvanic isolation is not required, non-isolated converters were reported as a suitable solution [20]

Based on non-isolated and resonant converter techniques, a non-isolated LLC resonant converter is presented in this paper. The proposed converter has combine advantages of resonant converter and nonisolation and will serve as a future alternative solution to voltage regulation and point of load converters some of the attractive features of the proposed topology are summarized as follows:

a. Balanced rectifying current and low thermal stress, this facilitates the use of components with the matched parameter for the rectifier circuit.

b. The conduction loss of the rectifier diodes can be optimized by using diodes with lower forward voltage drop.

c. Clamped voltage stress in all the semiconductor devices.

d. ZVS operation of all the primary switches over the entire operation range

e. The rest of this paper is organized as follows. Section II analyzes the resonant tank design for LLC resonant converter with high regulation capability. section III gives the experimental and simulation results of the proposed LLC converter. The conclusion is presented in section IV.

\section{ANALYSIS OF CONVERTER}

The proposed non-isolated LLC DC-DC converter is depicted in Figure 1. The converter consists of two bidirectional switches (M1 and M2) and a resonant LLC circuit $\left(L_{r}, L_{m}\right.$ and $\left.C_{r}\right)$. The switches are alternately commutated by applying a rectangular signal to their respective gates. The resonant capacitor $\mathrm{Cr}$ is connected in series with the inductor $L r$, while the inductor $L_{m}$ is connected in parallel with a full bridge rectifier. The converter basically supplies a square wave voltage generated by the half-bridge switching network to the resonant network. The energy is transferred to the load, connected across the full-bridge rectifier circuit.

\subsection{Analysis of Steady-State Operation of the Proposed Converter}

The steady-state analysis of the proposed converter is performed under the following assumptions that, a). The main switches are all MOSFETs with parasitic diodes and capacitance. b). The output capacitor $\left(C_{O}\right)$ is large enough to be considered as a voltage source $\left.\mathrm{c}\right)$. The output capacitances of the main switches (MOSFETs) are equal. d). All other components are considered as ideal.

Operation modes of the proposed converter can be divided into 4 intervals. Based on the foregoing assumption, the key steady-state waveforms of the converter are shown in Figure 2. The equivalent circuits of the operating intervals are also depicted in Figure 3.

Mode $1(\boldsymbol{t} \mathbf{0}<\boldsymbol{t} \leq \boldsymbol{t} \mathbf{1})$ : MOSFET M1 is tun-on with ZVS at $t=t_{0}$ due to the conduction of body diode DM1. Resonant inductor current flows in the positive direction, the magnetizing current $i_{L m}$ linearly increase as shown in Figure 3(a). During this period energy flow to the load through diodes D2 \& D3. The modes end at $\mathrm{t} 1$ with MOSFET M1 is turned off. 


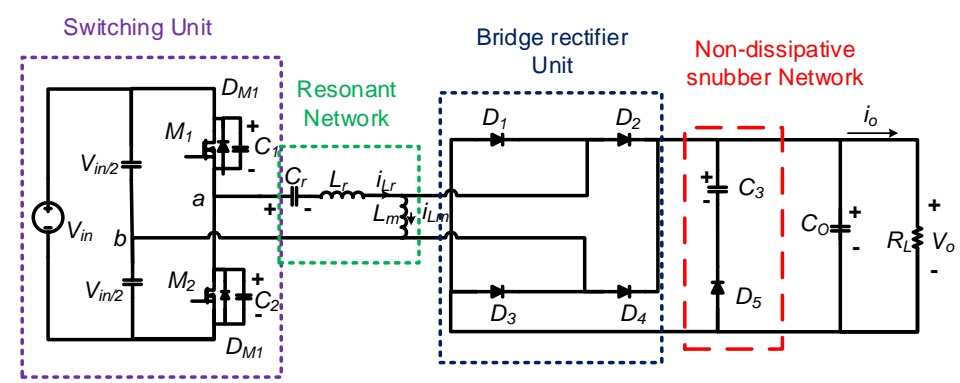

Figure 1. Schematic of the non-isolated LLC Converter

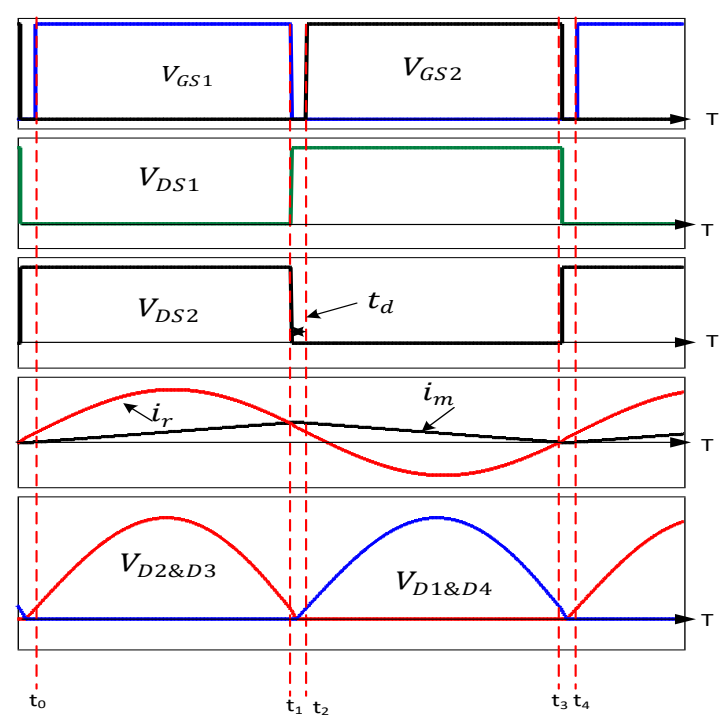

Figure 2. key steady-state waveforms of the proposed converter

Mode $2(\boldsymbol{t} \mathbf{1}<\boldsymbol{t} \leq \boldsymbol{t} 2)$ : At this interval switch, $M_{1}$ is turned-off at $t=t_{1}$, and the dead time $\left(t_{d}\right)$ starts. The resonant current $\left(i_{r}\right)$ quickly releases energy on the parasitic capacitor $C_{2}$ of MOSFET M2 and charges capacitor $C_{1}$ to $V_{i n}$, thereby flows through the diode $D_{M 2}$ clamping the drain-source voltage of MOSFETs M2 to zero. During this time, the resonant current $i_{r}$ is larger than magnetizing current $i_{m}$, The output rectifier diodes, D2 \& D3, conduct and continues to send energy to the load. Similarly, $\mathrm{Cr} \& \mathrm{Lr}$ resonate due to $L_{m}$ being clamped to the reflected output voltage $V o$ and the magnetizing current $i L m$ is at its peak positive value as shown in Figure 3(b).

Mode $3(\boldsymbol{t} 2<\boldsymbol{t} \leq \boldsymbol{t} \mathbf{3})$ : MOSFET $M_{2}$ is turned on at $t=t 2$ with ZVS due to the conduction of its body diode DM2. During this interval, resonant current $\left(i_{r}\right)$ decrease negatively flowing through the MOSFET switch $M_{2}$. The magnetizing inductor current $\left(i_{L m}\right)$ linearly decreases from its peak positive value. However, diodes D1, D4 \& D5 continue to conduct and deliver power to the load, this mode ends at $t=t_{3}$. The resonant current is the sum of magnetizing current and the output inductor current as shown in Figure 3(c).

Mode 4 ( $\boldsymbol{t} 3<\boldsymbol{t} \leq \boldsymbol{t 4})$ : During this interval, switch, $M_{1} \& \mathrm{M} 2$ maintains turned-off at $t=t_{3}$, and the second dead time $\left(t_{d}\right)$ starts. The resonant current $\left(i_{r}\right)$ quickly discharge capacitor $C_{1}$ while charges capacitor $C_{2}$. Resonant current $I_{r}$ flows through diode $D_{M 1}$ whereas, the drain-source voltage of MOSFETs M1 is clamped to zero. The output rectifier diodes D1 \& D4 conduct and supply energy to the load as shown in Figure 3(d). The mode ends at $t=t_{4}$.

To simplify the analysis of the converter circuit, the non-linear circuit model of the converter can be replaced by a linear and time-invariant circuit. The linear circuit model is based on the first harmonic approximation (FHA), full details can be found in [21-24]. An LLC converter can be represented by its equivalent circuit model as depicted in Figure 4. 


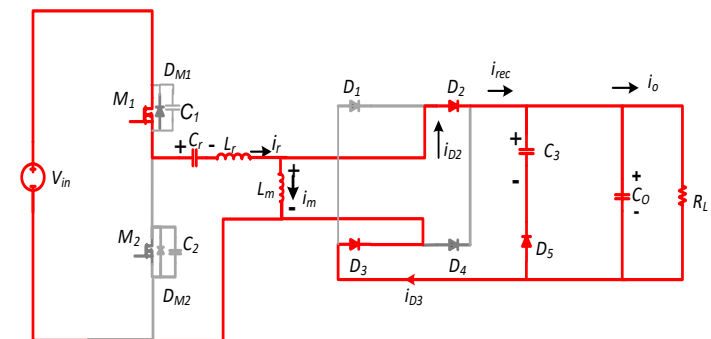

(a)

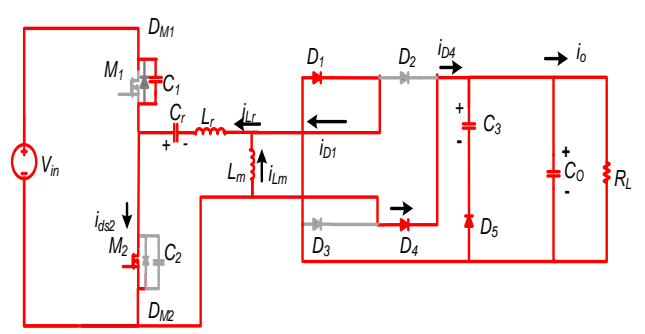

(c)

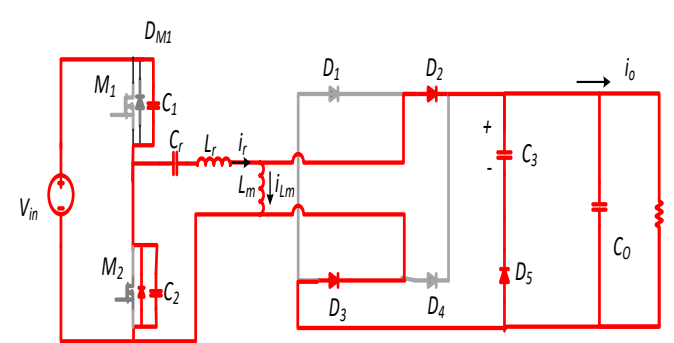

(b)

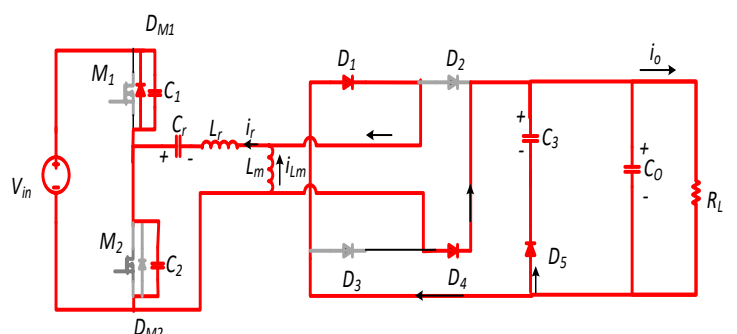

(d)

Figure 3. The equivalent circuits of the operating intervals (a) Mode 1 (b) mode 2. (c) mode 3 and, (d) mode 4

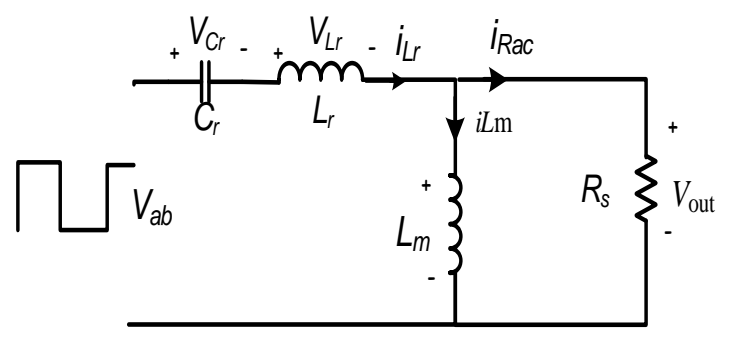

Figure 4. Equivalent circuit of the proposed LLC converter

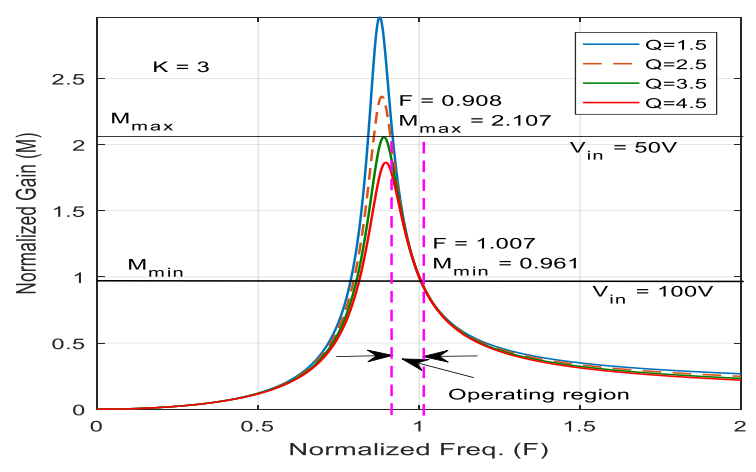

Figure 5. Normalized gain versus normalized frequency of curve the proposed converter

From the equivalent circuit Figure 4, the equivalent ac resistance and voltage conversion ratio are calculated as:

$$
\begin{aligned}
& R_{a c}=\frac{8 R_{L}}{\pi^{2}} \\
& M(Q, F, k)=\frac{2 V_{O}}{V_{\text {in }}}=\frac{1}{2 \sqrt{\left(Q F\left(1-\frac{1}{F^{2}}\right)\right)^{2}+\left(1+k-\frac{k}{F^{2}}\right)^{2}}} \\
& \text { where } Q=\omega_{o} L / R_{a c}, F=f_{s} / f_{r}, k=L_{r} / L_{m}, f_{r}=1 / 2 \pi \sqrt{\left(L_{r} C_{r}\right)}
\end{aligned}
$$

As shown in (2) is used to obtain the plot of normalized dc gain against normalized frequency for different values of quality factor $(\mathrm{Q})$ as depicted in Figure 5. The curve is drawn to show the relationships between load, voltage gain, switching frequency, and the resonant frequency respectively. The maximum value of the normalized gain for the selected inductor ratio is shown, furthermore, the corresponding range of operating frequency to satisfy the gain conditions are indicated accordingly. 
From the trajectory of Figure 5, inductor ratio $(\mathrm{k})$ and quality factor $(\mathrm{Q})$ are selected based on the operating points, these values are used to determine the values of the resonant inductor $\left(L_{r}\right)$ and resonant capacitor $\left(C_{r}\right)$ respectively.

\subsection{Component Design for the Proposed Converter}

Selection of resonant tank elements $\left(L_{r}, C_{r}\right.$ and $\left.L_{m}\right)$ values can be considered as the most important part of converter design, due to their significant role in maintaining ZVS operation within a particular operating point [25], [26] and in regulating the energy transfer. A lower value of magnetizing inductor $\left(L_{m}\right)$ reduce core losses and increase the converter gain due to low inductor ratio (k), perhaps, at the expense of high circulating current. Proper selection of resonant components $\left(L_{r}\right.$ and $\left.C_{r}\right)$ values, reduce the converter maximum input current, this led to reduce circulating current and conduction losses [5].

Values of resonant elements are determined using the following equations:

$$
\begin{aligned}
C_{r} & =\frac{1}{\omega_{o} Q R_{a c}} \\
L_{r} & =\frac{Q R_{a c}}{\omega_{O}} \\
L_{m} & =k L_{r}
\end{aligned}
$$

Peak voltage across the resonating capacitor is;

$$
V_{C r}(\max ) \cong \frac{V_{\text {in }}(\max )}{2}+\frac{\sqrt{2} \cdot I_{c r}(r m s)}{2 \pi f_{o} C_{r}}
$$
given as [5].

The root means square (RMS) current circulating in the resonant inductor and capacitor is

$$
I_{l r_{-} r m s}=\frac{1}{8} \frac{V_{O}}{n R_{L}} \sqrt{\frac{2 n^{4} R_{L}^{2} T^{2}}{L_{m}^{2}}+8 \pi^{2}}
$$

Thus, the RMS value of magnetizing current is,

$$
\begin{aligned}
& I_{m}(r m s)=\frac{2 \sqrt{2}}{\pi} \times \frac{n \times V_{o}}{\omega L_{m}} \\
& \text { Similarly, } I_{m}=\frac{2 C_{e q} V_{\text {in }}}{t_{\text {dead }}}
\end{aligned}
$$

Where $I_{m}$ is the peak magnetizing current during the dead time; $t_{\text {dead }}$ is the dead time, $C_{e q}$ is MOSFET equivalent output capacitances, and $V_{i n}$ is the LLC bus voltage.

The value of the output capacitor to maintain a constant DC output voltage is given as:

$$
C_{o} \geq \frac{I_{O}}{2 \omega \Delta V_{c o}}
$$

\section{EXPERIMENTAL RESULTS}

To verify the effectiveness of the analyses of non-isolated LLC converter a 60W 100-48V LLC resonant dc-dc converter was simulated with a PSIM circuit simulator and a laboratory prototype was designed to validate the concept and demonstrates the circuit performance. Figure 6 . shows the photograph of the experimental set-up of the proposed converter. Table 1. Shows the specification of the proposed converter considered for the experiment and simulation. 


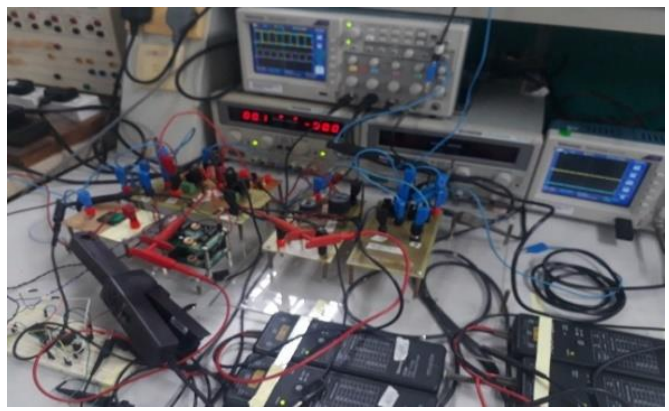

Figure 6. Experimental test setup

Table 1. Converter Specification

\begin{tabular}{ll}
\hline Electrical specification & Values \\
\hline Max. Output power (Po) & $60 \mathrm{~W}$ \\
Output Voltage $($ Vout $)$ & $48 \mathrm{~V}$ \\
Input Voltage $($ Vin $)$ & $50-100 \mathrm{~V}$ \\
Switching frequency $(f s)$ & $100 \mathrm{kHz}$ \\
Resonant Frequency $(f r)$ & $80 \mathrm{kHz}$ \\
Component parameters & \\
Resonant Inductor $(\mathrm{Lr})$ & $155 \mu \mathrm{H}$ \\
Magnetizing Inductor $(\mathrm{Lm})$ & $465 \mu \mathrm{H}$ \\
Resonant capacitor $(\mathrm{Cr})$ & $26 \mathrm{nF}$ \\
Output capacitor $\left(C_{o}\right)$ & $100 \mu F$ \\
Power switch & $\mathrm{IRFP} 4568 \mathrm{PbF}$ \\
Diodes $\mathrm{D}_{1}-\mathrm{D}_{4}$ & $\mathrm{MUR} 1560 \mathrm{G}$ \\
\hline
\end{tabular}

Figure 7 show the full-load ZVS operation of upper and lower side MOSFETs respectively. Figure 7(a) Illustrates the experimental waveforms of the upper side MOSFET (M1) control signal, current, and voltages of the MOSFET at full load respectively. According to the experimental results, all the semiconductor elements are softly commuted.

Figure 7(b) shows the experimental waveforms of the control signal, current and voltages of the lower side MOSFET M2 respectively. It can be observed that current $i_{d s} 2$ lags $V_{d s} 2$, create a zero-voltage condition for MOSFET $M_{2}$.

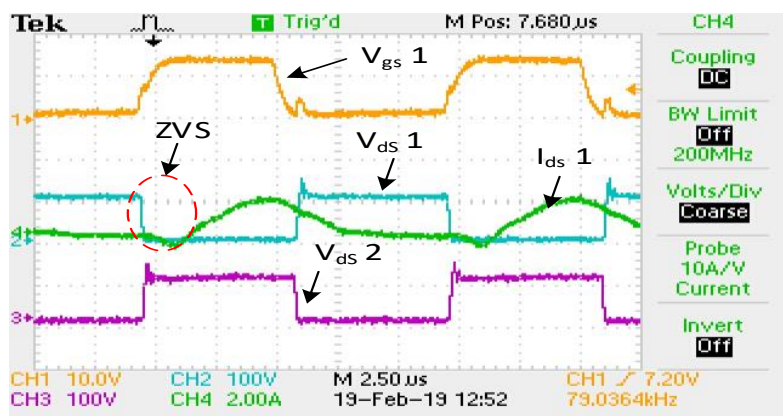

(a)

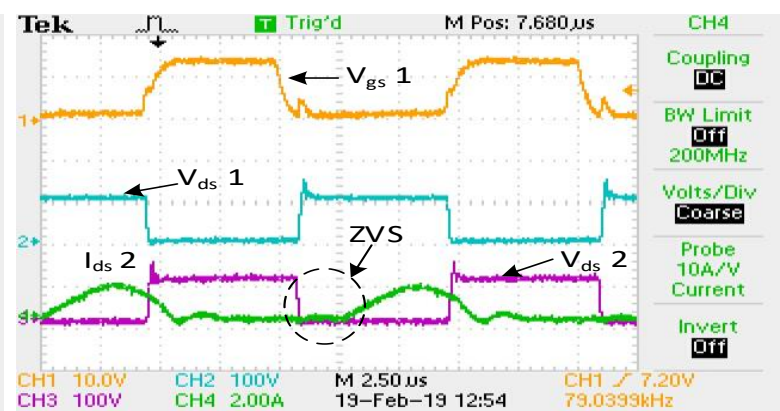

(b)

Figure 7. Full-load ZVS waveforms of power MOSFETs (a) The experimental waveform of the upper side MOSFET: $\mathrm{CH} 1)$ gate-source voltage $\mathrm{M} 1, \mathrm{CH} 2$ ) drain-source voltage of $\mathrm{M} 1, \mathrm{CH} 3$ ) drain-source voltage of M2, CH4 drain-source current of M1 respectively. (b) The experimental waveform of the Lower side MOSFET

Figure 8. shows the gates source signal and drain-source voltage of the power MOSFET at no-load. From Figure 8. It can be observed that all the power switches are operated with ZVS. 


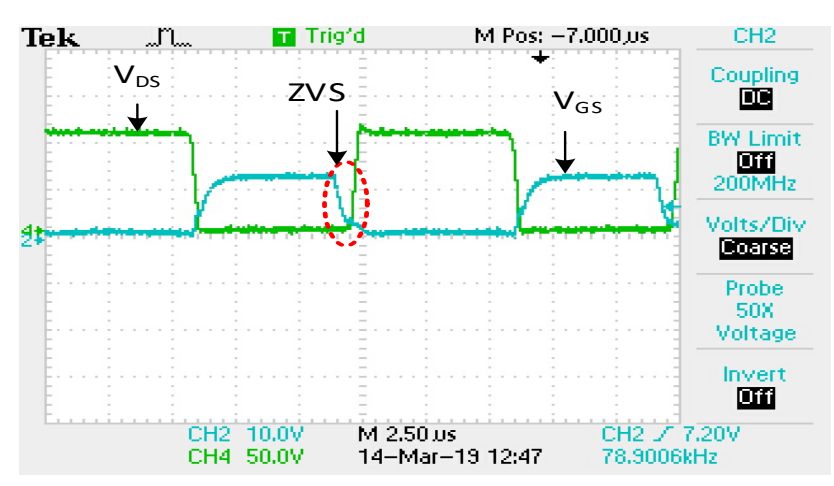

Figure 8. ZVS at no-load. CH1) drain-source of M1, CH2) drain-source current of M1

Figure 9. illustrates the simulated and experimental rectified waveforms accordingly. Figure 9. (a) is the simulation result of the isolated type LLC resonant converter, showing an unbalanced the rectified secondary current. This results in component mismatch and current stress in the leading leg diodes. In Figure 9(b) a simulated voltage and current waveform of the proposed converter is illustrated. Figure 9(c) shows the experimental rectified current waveform of the proposed converter. From Figure 9(c), it is evident that no extra current stress on the rectifier diodes. In addition, the experimental results are compatible with the simulation results. In either case, the rectifier diodes are turned on under zero current switching (ZCS).

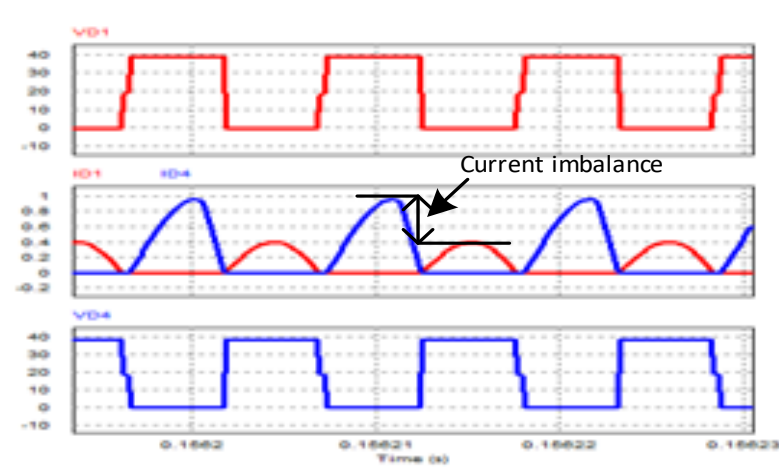

(a)

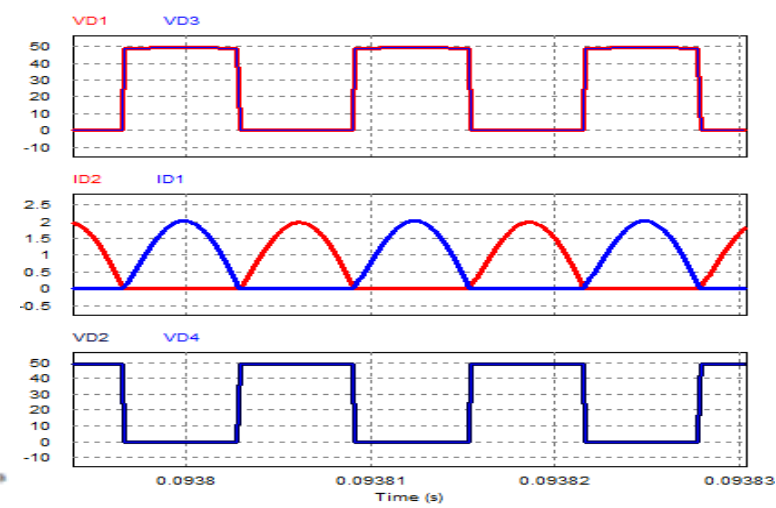

(b)

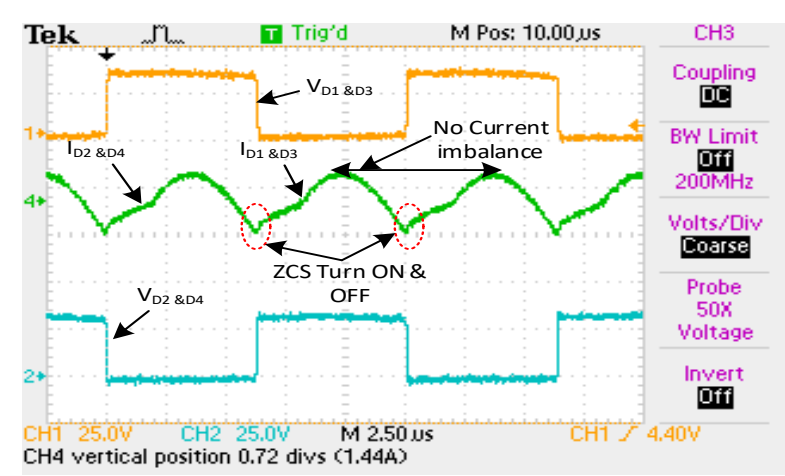

(c)

Figure 9. Simulated and experimental rectified waveforms. (a) The simulated waveform of isolated LLC converter, (b) Simulated waveform of Proposed non-isolated LLC converter, (c) Experimental waveform of the proposed non-isolated LLC 
Figures 10(a) \& (b) depicts the simulated and experimental voltage and current waveforms of the proposed converter. As shown in the simulated gate control signal, the voltage across the resonant capacitor, the voltage across the lower side MOSFET and the current through the resonant network, simulation and experimental results are identical.

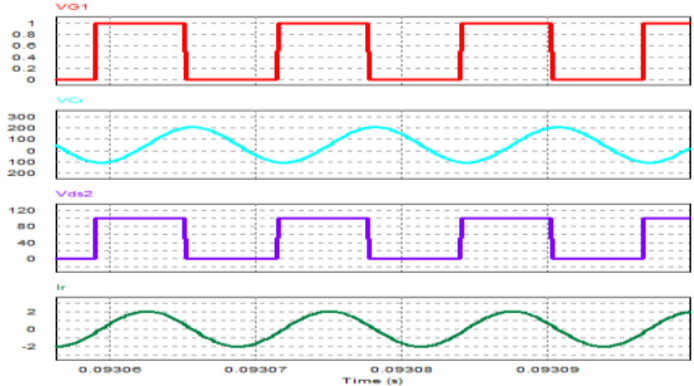

(a)

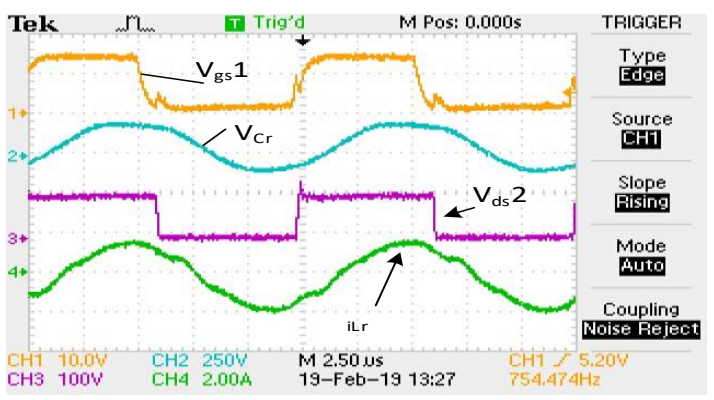

(b)

Figure 10. Simulated and Experimental waveforms of resonant elements (a) simulated waveform. (b) experimental waveform $\mathrm{CH} 1$ ) gate-source voltage of $\mathrm{M} 1, \mathrm{CH} 2$ ) voltage across the resonant capacitor, $\mathrm{CH} 3$ ) drain-source voltage of M2, CH4) current through the resonant tank

\section{CONCLUSIONS REFERENCES}

This paper has presented, analyzed and verified a 60W non-isolated LLC converter with balanced rectifying current and ZVS operation over the entire operating range. By appropriate design of resonant parameters, the resonant imbalance can be avoided. Similarly. Simple structure and good resonant characteristics are ensured. The desirable ZVS turn-on feature is accomplished. The experimental results verify the validity of the proposed concept.

\section{REFERENCES}

[1] J. H. Kim, M. Y. Kim, C. O. Yeon, and G. W. Moon, "Analysis and design of Boost-LLC converter for high power density AC-DC adapter," 2013 IEEE ECCE Asia Downunder - 5th IEEE Annu. Int. Energy Convers. Congr. Exhib. IEEE ECCE Asia 2013, no. Iec 61000, pp. 6-11, 2013.

[2] T. Ou et al., "A Novel Transformer Structure Used in a 1.4 MHz LLC Resonant Converter with GaNFETs," Proc. 2018 IEEE Int. Power Electron. Appl. Conf. Expo. PEAC 2018, pp. 1-5, 2018.

[3] I. H. Cho, Y. Do Kim, and G. W. Moon, "A half-bridge LLC resonant converter adopting boost PWM control scheme for hold-up state operation," IEEE Trans. Power Electron., vol. 29, no. 2, pp. 841-850, 2014.

[4] J. W. Kim, M. Lee, and J. S. Lai, "Efficient LLC Resonant Converter with a Simple Hold-Up Time Compensation in Voltage Doubler Rectifier," IEEE J. Emerg. Sel. Top. Power Electron., vol. 7, no. 2, pp. 843-850, 2019.

[5] B. Lu, W. Liu, Y. Liang, F. C. Lee, and J. D. Van Wyk, "Optimal Design Methodology for LLC Resonant Converter," Twenty-First Annu. IEEE Appl. Power Electron. Conf. Expo. 2006. APEC '06., pp. 533-538, 2006.

[6] Jee-hoon Jung and Joong-gi Kwon, "Theoretical Analysis and Optimal Design of LLC Resonant Converter," 2007 Eur. Conf. Power Electron. Appl., pp. 1-10, 2007.

[7] D. Huang, F. C. Lee, and V. Tech, "Classification and Selection Methodology for multi-element Resonant Converters," in Applied Power Electronics Conference and Exposition, 2011. APEC '11. Conference Proceedings 2011., Twenty-sixth Annual, 2011, pp. 558-565.

[8] A. M. Dobi, M. R. Sahid, and T. Sutikno, "Overview of Soft-switching DC-DC Converters," Int. J. Power Electron. Drive Syst., vol. 9, no. 4, pp. 2006-2018, 2018.

[9] D. D. Tran, H. N. Vu, S. Yu, and W. Choi, "A Novel Soft-Switching Full-Bridge Converter with a Combination of a Secondary Switch and a Nondissipative Snubber," IEEE Trans. Power Electron., vol. 33, no. 2, pp. 1440-1452, 2018.

[10] J. H. J. J. . C. J. G. Kwon, "Design Methodology for Transformers Including Integrated and Center-tapped Structures for LLC Resonant Converters," J. Power Electron., vol. 9, no. 2, pp. 215-223, 2009.

[11] H. de Groot, E. Janssen, R. Pagano, and K. Schetters, "Design of a 1-MHz LLC resonant converter based on a DSP-driven SOI half-bridge power MOS module," IEEE Trans. Power Electron., vol. 22, no. 6, pp. 2307-2320, 2007.

[12] M. Noah et al., "A Current Sharing Method Utilizing Single Balancing Transformer for a Multiphase LLC Resonant Converter with Integrated Magnetics," IEEE J. Emerg. Sel. Top. Power Electron., vol. 6, no. 2, pp. $977-$ 992, 2018.

[13] K. Murata and F. Kurokawa, "An Interleaved PFM LLC Resonant Converter With Phase-Shift Compensation," IEEE Trans. power Electron., vol. 31, no. 3, pp. 2264-2272, 2016. 
[14] M. Yamamoto et al., "Magnetic Design and Experimental Evaluation of a Commercially Available Single Integrated Transformer in Three-Phase $<$ italic $>$ LLC $<$ /italic $>$ Resonant Converter," IEEE Trans. Ind. Appl., vol. 54, no. 6, pp. 6190-6204, 2018.

[15] D. Sha, X. Wang, K. Liu, and C. Chen, "A Current-Fed Dual-Active-Bridge DC-DC Converter Using Extended Duty Cycle Control and Magnetic-Integrated Inductors with Optimized Voltage Mismatching Control," IEEE Trans. Power Electron., vol. 34, no. 1, pp. 462-473, 2019.

[16] D. Liu, F. Deng, Q. Zhang, and Z. Chen, "Zero-Voltage Switching PWM Strategy Based Capacitor CurrentBalancing Control for Half-Bridge Three-Level DC/DC Converter," IEEE Trans. Power Electron., vol. 33, no. 1, pp. 357-369, 2018.

[17] S. Chen, L. Zhou, Q. Luo, and B. Zhu, "Interleaved non-isolated high step-up DC/DC converter based on the diode-capacitor multiplier," IET Power Electron., vol. 7, no. 2, pp. 390-397, Feb. 2014.

[18] D. Huang, X. Wu, and F. C. Lee, "Novel non-isolated LLC resonant converters," Conf. Proc. - IEEE Appl. Power Electron. Conf. Expo. - APEC, pp. 1373-1380, 2012.

[19] T. Selmi and M. Rezgui, "A Novel DC-AC Inverter Topology to Eliminate Leakage Current," Int. J. Power Electron. Drive Syst., vol. 9, no. 4, p. 1733, 2018.

[20] R. H. Ashique and Z. Salam, "A High-Gain, High-Efficiency Nonisolated Bidirectional DC-DC Converter with Sustained ZVS Operation," IEEE Trans. Ind. Electron., vol. 65, no. 10, pp. 7829-7840, 2018.

[21] R. Beiranvand, B. Rashidian, M. R. Zolghadri, and S. M. H. Alavi, "Using LLC resonant converter for designing wide-range voltage source," IEEE Trans. Ind. Electron., vol. 58, no. 5, pp. 1746-1756, 2011.

[22] R. L. Steigerwald, "A comparison of half-bridge resonant converter topologies," APEC 1987 - 2nd Annu. IEEE Appl. Power Electron. Conf. Expo. Conf. Proc., vol. 3, no. 2, pp. 135-144, 2015.

[23] H. Huang, "FHA-based voltage gain function with harmonic compensation for LLC resonant converter," Conf. Proc. - IEEE Appl. Power Electron. Conf. Expo. - APEC, pp. 1770-1777, 2010.

[24] S. De Simone, C. Adragna, C. Spini, and G. Gattavari, "Design-oriented steady-state analysis of LLC resonant converters based on FHA," Int. Symp. Power Electron. Electr. Drives, Autom. Motion, 2006. SPEEDAM 2006., no. June, pp. 200-207, 2006.

[25] C. Iannello, S. Luo, and I. Batarseh, "Full bridge ZCS PWM converter for high-voltage high-power applications," IEEE Trans. Aerosp. Electron. Syst., vol. 38, no. 2, pp. 515-526, 2002.

[26] H. P. Park and J. H. Jung, "PWM and PFM Hybrid Control Method for LLC Resonant Converters in High Switching Frequency Operation," IEEE Trans. Ind. Electron., vol. 64, no. 1, pp. 253-263, 2017.

\section{BIOGRAPHIES OF AUTHORS}

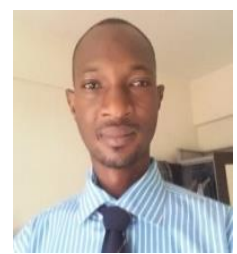

AbdulHakeem Mohammed Dobi obtained his B.Eng and M.Eng in Electrical Engineering from Bayero University, Kano Nigeria, in 2005 and 2012 respectively. Currently, he is pursuing a Ph.D. in power electronics at the Universiti Teknologi Malaysia (UTM) Johor Bahru. His research interest includes Soft switching, Resonance DC-DC converters, and their control aspects.

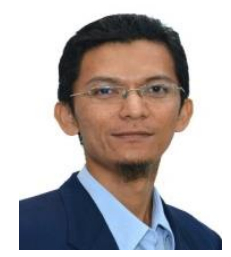

Dr. Mohd Rodhi Bin Sahid is a senior lecturer in the Department of Electrical Power system, Universiti Teknologi Malaysia, Johor Bahru Malaysia. He obtained B.Eng.; M. Eng and Ph.D. in Electrical Engineering in 2012. He has published many papers in the field of power electronics. His area of interest includes power factor correction, DC-DC converters. 